\title{
El manejo fiscal: revisión técnica de su realidad en el Ecuador, 2000-2019
}

Fiscal Management: Technical Review of its Reality in Ecuador, 2000-2019

A gestão fiscal: revisão técnica da realidade no Equador entre 2000 e 2019

\author{
Carlos de la Torre \\ Universidad UTE. Quito, Ecuador \\ carlosa.delatorre@ute.edu.ec \\ https://orcid.org/0000-0003-1848-7075
}

DOI: https://doi.org/10.32719/25506641.2021.9.3

Recibido: 26 de junio de 2020 • Revisado: 27 de julio de 2020

Aceptado: 18 de agosto de 2020

Artículo de investigación

Licencia Creative Commons

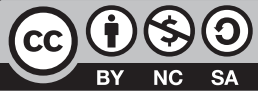




\section{Resumen}

El debate en materia fiscal, en Ecuador ha sido permanente, al menos en la historia reciente del país, pero en los últimos años ha generado un mayor interés por diversas circunstancias, particularmente debido a cambios importantes en la evolución de variables de la gestión pública. En este tiempo, diversas voces han hecho públicos algunos datos sobre el manejo fiscal, los que, en muchos casos, no se han ajustado ni a la realidad ni a los hechos, sino que se han constituido en insumos para la construcción de diversos relatos adecuados a visiones particulares respecto de la economía ecuatoriana. Del contraste de estos relatos con fundamentos teóricos y técnicos, sustentados en información cuantitativa oficial disponible, se demuestra que buena parte del debate actual se desarrolla lejos de la utilización de evidencias y de sólidas bases teóricas. Este artículo sistematiza este contraste a efectos de proponer un nuevo relato apegado a la realidad desde una perspectiva técnica y académica. De este ejercicio se concluye que buena parte de las afirmaciones y conceptos que, en materia fiscal, son de dominio público, difieren sustancialmente de lo que presentan las cifras y ampara la norma.

Palabras clave: ingresos, gasto, deuda, y déficit fiscal.

JEL: H2 Tributación, subvenciones e ingreso.

\section{Abstract}

The debate on fiscal matters in Ecuador has been permanent at least in the recent history of the country, but in recent years it has generated greater interest due to various circumstances, particularly due to important changes in the variables evolution of public management. During this time, a few people have made public some data on fiscal management, which, in many cases, has not been adjusted to reality or to the facts, but has become inputs for the construction of various adequate accounts to particular visions regarding the Ecuadorian economy. From the contrast of these reports with theoretical and technical foundations, supported by available official quantitative information, it is shown that much of the current debate takes place far from the use of evidence and solid theoretical bases. This article systematizes this contrast in order to propose a new story, attached to reality from a technical and academic perspective. From this exercise it is concluded that a good part of the statements and concepts that, in tax matters, is in the public domain, differ substantially from what the figures present and are covered by the standard.

Keywords: Income, spending, debt, and fiscal deficit.

JEL: H2 Taxation, subsidies, revenues, general.

\section{Resumo}

No Equador, o debate em matéria fiscal é algo permanente, pelo menos na história recente do país. No entanto, nos últimos anos, isso tem gerado um maior interesse por diversas circunstâncias, particularmente devido a importantes mudanças na evolução de variáveis da gestão pública. Durante tal período, diversas vozes tornaram públicos alguns dados sobre a gestão fiscal, os quais, em muitos casos, não se ajustaram nem à realidade nem 
aos fatos, tornando-se insumos para a construção de diversos relatos adequados a visões particulares a respeito da economia equatoriana. A partir do contraste de tais relatos com fundamentos teóricos e técnicos, sustentados por informações quantitativas oficiais disponíveis, demonstra-se que boa parte do debate atual se desenvolve longe da utilização de evidências e de sólidas bases teóricas. O presente artigo sistematiza esse contraste de forma a propor um novo relato, apegado à realidade a partir de uma perspectiva técnica $\mathrm{e}$ acadêmica. Com tal exercício, conclui-se que boa parte das afirmações e conceitos que, em matéria fiscal, são de domínio público, diferem substancialmente do que apresentam as cifras e daquilo que é amparado pela norma.

Palavras-chave: Rendas, gasto, dívida e déficit fiscal.

JEL: H2 Tributação, subsídios e renda.

\section{Introducción}

$\mathrm{H}$ istóricamente en Ecuador, el manejo fiscal se ha interpretado desde la visión de analistas y expertos desde un enfoque minimalista que se ha reducido a evaluar unas pocas variables contables como son el gasto público, el déficit fiscal, las deudas externa y pública, y los ingresos petroleros. Esta visión se mantiene en la actualidad con un ingrediente adicional: la utilización y análisis de estas variables para la construcción de un relato negativo de la participación del Estado en la economía en los últimos años.

De esta manera, se ha ignorado completamente el rol fundamental que tiene en una economía la política fiscal, como el eje principal en el que se asienta el crecimiento económico, la redistribución del ingreso y de la riqueza, $y$, principalmente, la construcción de capacidades productivas de una economía a través del levantamiento de infraestructura y de la formación de talento humano (CEPAL 2018b).

Contrariamente al papel del Estado en una economía, cuyas funciones son ampliamente respaldadas por la práctica, incluso en países desarrollados e identificados como capitalistas, los argumentos locales pretenden implantar en el imaginario social que Ecuador sufre de un Estado obeso, con niveles de sobreendeudamiento, con un gasto público insostenible y, de esta manera, todo un conjunto de adjetivaciones absolutas sin ningún tipo de comparación o contraste que permita relativizar estas variables y así sustentar los calificativos que las preceden (Carrera 2020). 
En contraposición a los esfuerzos de ciertos sectores, de valerse de verdaderas líneas argumentales, que claramente no buscan describir la realidad, las siguientes líneas se orientan a presentar la situación fiscal de la economía ecuatoriana desde una perspectiva técnica y mediante el uso de información estadística oficial validada internacionalmente. ${ }^{1}$

\section{La dependencia de los ingresos fiscales en el petróleo}

Casi a nivel de mito, se ha generalizado en Ecuador la idea de que los ingresos por las exportaciones petroleras han constituido históricamente el grueso de los recursos con los que se alimenta la caja fiscal, por poco constituyendo su determinante. Los datos ciertamente dan cuenta de una importancia no menor de los ingresos por exportaciones petroleras, pero debe notarse que a lo largo de las últimas dos décadas su participación en las rentas fiscales se ha reducido de forma considerable. Esta trayectoria descendente se profundizó con el colapso abrupto de los precios del petróleo en el último trimestre de 2014, lo que ha obligado a que el Presupuesto General del Estado (PGE) dependa en mayor medida de la principal fuente de ingresos permanentes que es la recaudación tributaria (gráfico 1).

Es importante también observar que los ingresos por exportaciones petroleras en la ejecución presupuestaria han evolucionado a la par de los precios internacionales del hidrocarburo. De esta manera, si bien cada vez es menor la dependencia del PGE en los ingresos petroleros, su volatilidad y participación en los ingresos totales están marcadas indefectiblemente por los precios del hidrocarburo (gráfico 2).

1. Las estadísticas de las finanzas públicas ecuatorianas, así como la información estadística económica oficial bajo la responsabilidad del Banco Central del Ecuador, Instituto Ecuatoriano de Estadística y Censos y Ministerio de Economía y Finanzas, entre las entidades más importantes, se elaboran bajo estándares internacionales y son continuamente supervisadas desde los principales organismos multilaterales que conforman la institucionalidad global en el campo económico y financiero. 
Gráfico 1

Participación de los ingresos por exportaciones petroleras en los ingresos del PGE en porcentajes sobre valores devengados*

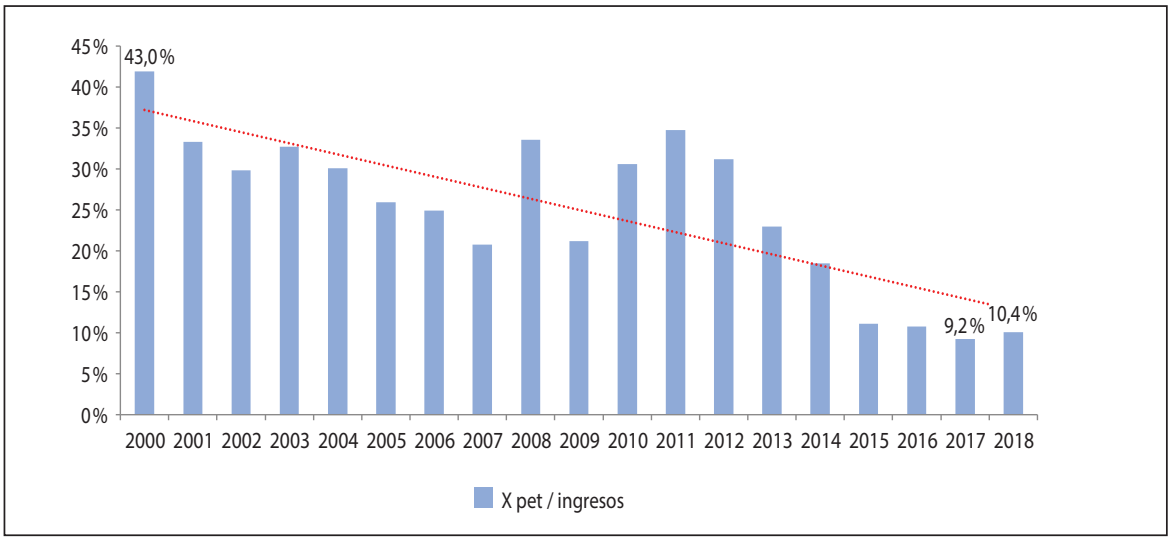

* 2000-2018. La línea de tendencia se generó automáticamente como función lineal.

Fuente: BCE (2020).

\section{Gráfico 2}

\section{Ingresos por exportaciones petroleras, ingresos del PGE y precios de petróleo*}

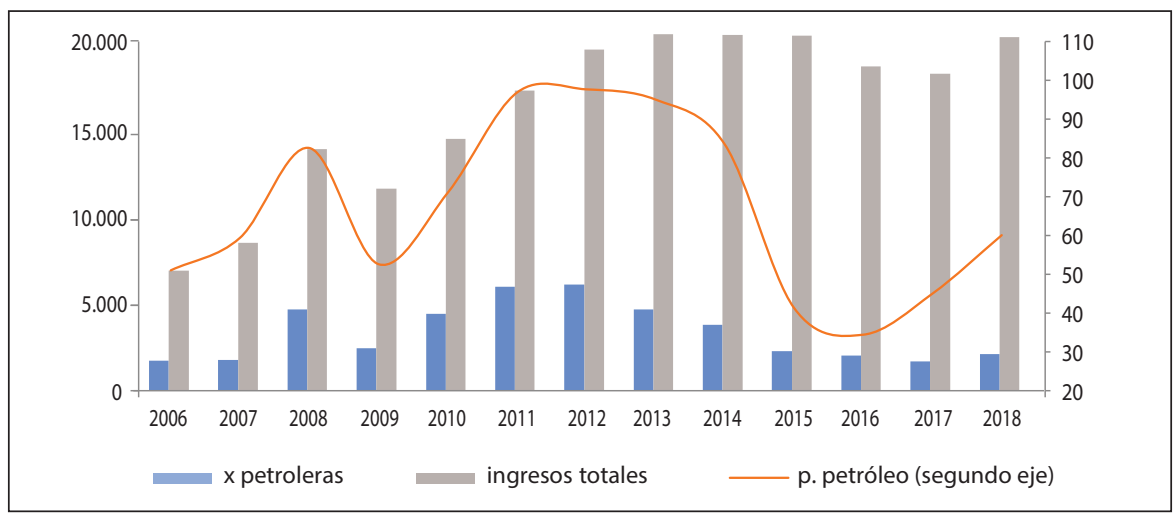

* Corresponde al promedio anual de la cesta de crudos Oriente y Napo.

En millones de dólares, 2006-2018.

Fuente: BCE (2020). 
De este primer análisis se desprende que, si bien la dependencia de los ingresos fiscales en los ingresos petroleros presenta una trayectoria descendente en el largo plazo, su evolución de corto plazo está marcada en gran medida por los precios, lo cual presenta un factor importante de riesgo de la economía ecuatoriana frente a shocks externos.

Por otra parte, mediante el cálculo de la elasticidad de los ingresos fiscales por exportaciones petroleras respecto de los precios del hidrocarburo, se observa entre 2007 y 2018, principalmente, valores elásticos, excepto durante el período 2015-2018. Esto denota que la respuesta de los ingresos petroleros usualmente ha sido muy sensible a las variaciones de los precios del petróleo (gráfico 3).

Esta situación resulta de la poca o nula incidencia de los volúmenes de petróleo en los ingresos obtenidos de su exportación en virtud de que estos se mantienen constantes, lo cual es resultado de un estancamiento de largo plazo en la capacidad de extracción de crudo en el país.

La excepción a este comportamiento inicia en 2015, poco después del colapso de los precios internacionales del petróleo cuyo descenso abrupto se produjo en el tercer trimestre de 2014. La explicación de la inelasticidad a la baja de los ingresos petroleros entre 2015 y 2018 se fundamenta en un incremento temporal en las exportaciones (en volumen) motivado precisamente por el alza sostenida de los precios internacionales del petróleo en los años anteriores. $^{2}$

En el gráfico 3 resulta relevante el valor negativo de la elasticidad calculada para 2017 en un contexto de recuperación de los precios internacionales del petróleo, situación que precede a un valor todavía inelástico para 2018, pero ya en sentido ascendente. En términos del manejo fiscal, esto evidencia una respuesta, primeramente, contraria de los ingresos por exportaciones petroleras en la ejecución presupuestaria respecto del incremento en los precios y, luego, poco sensible. En principio, esto podría reflejar un cambio importante en la política fiscal en términos de los mecanismos definidos para alimentar la caja fiscal, pero la realidad implica un manejo de ingresos fiscales

2. De acuerdo con el Reporte del Sector Petrolero IV Trimestre 2017 del BCE, las exportaciones de crudo nacionales se redujeron entre 2015 y 2017, pero los totales se incrementaron por las exportaciones realizadas por las empresas extranjeras. 


\section{Gráfico 3}

\section{Ingresos por exportaciones petroleras, ingresos del PGE y precios de petróleo*}

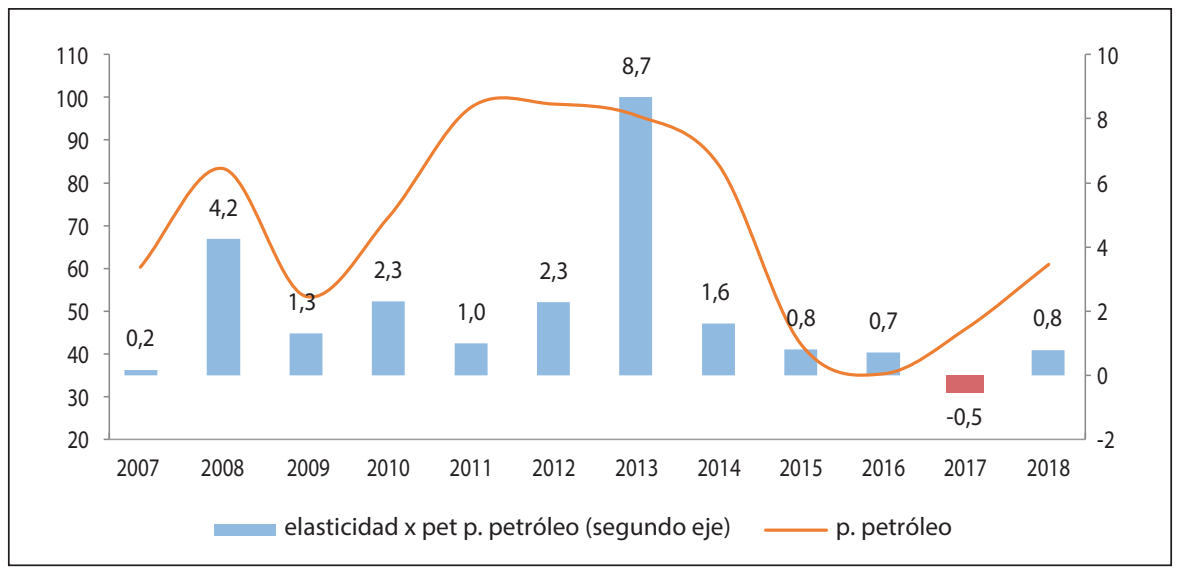

* Corresponde al promedio anual de la cesta de crudos Oriente y Napo.

En millones de dólares, 2006-2018.

Fuente: BCE (2020).

establecido para un escenario de descenso de precios que, ante su incremento no esperado, no cambió su sentido principalmente por rigideces normativas o contractuales en cuanto a la distribución total de ingresos petroleros (pagos a empresas petroleras y otros actores beneficiarios).

En resumen, la dependencia de los ingresos fiscales en las exportaciones petroleras del país es todavía importante, pero, a lo largo de los años, su relevancia ha ido decreciendo, al menos hasta 2018. Esta participación, cada vez menor, de los ingresos por exportaciones petroleras en la ejecución presupuestaria es importante en términos de la consecuente reducción de la dependencia en esta fuente, determinada por la volatilidad de sus precios internacionales por fuera de las capacidades locales de su control. 


\section{Deuda pública y sus efectos en la economía nacional}

\section{Las cifras de la deuda como instrumento político}

Una de las variables relevantes del manejo fiscal, al menos en el espacio de la opinión pública, es la deuda del gobierno. Su importancia radica en el aprovechamiento que se puede hacer de la concepción negativa que tiene la deuda en el imaginario popular de los ecuatorianos.

El protagonismo de la deuda pública en la arena política de los dos últimos años inició con un examen especial y la conformación de una veeduría ciudadana impulsadas a inicios de enero de 2018 por la Contraloría General del Estado (CGE) (El Comercio 2018a). Con estas acciones, y particularmente con la conformación de esta veeduría, cuya legalidad ha estado en entredicho, se desataron una serie de valoraciones y cuestionamientos de la deuda pública desde diversos sectores de la sociedad, amplificados por los medios de comunicación, siempre en un sentido negativo, en especial en lo referente a su contratación y valor alcanzado durante el período 2007-2017. Lo que se procuró en este sentido fue el posicionamiento mediático de que, a fines de ese período presidencial, se superó el límite normado de la deuda pública del $40 \%$ del PIB (EC 2010), ${ }^{3}$ luego de un proceso de contratación de financiamiento agresivo, lo cual generaría incluso responsabilidades de orden penal a las autoridades gubernamentales anteriores.

Del examen especial que llevó a cabo la CGE respecto del endeudamiento interno y externo, el contralor subrogante indicaba en abril de 2018 que "el informe de Contraloría, más allá de dar una cifra de deuda, está planteando la existencia de un conjunto de rubros que no se consideraron en el cálculo y, por tanto, pone en duda el monto exacto de la deuda" (El Comercio 2018d).

Por su parte, del informe indicado y de declaraciones de los miembros de la veeduría ciudadana, la prensa daba cuenta, en abril de 2018, que al fin de 2016 "el total de pasivos ascendió a USD 65.749 millones, esto incluye pre-

3. El art. 124 del Código Orgánico de Planificación y Finanzas Públicas (EC 2010) establece: "Límite al endeudamiento público.- El monto total del saldo de la deuda pública realizada por el conjunto de las entidades y organismos del sector público, en ningún caso podrá sobrepasar el cuarenta por ciento (40\%) del PIB". 
ventas de crudo, deuda a entidades públicas y contingentes. Esto representa el 68,4 \% del PIB de ese año" (El Comercio 2018c).

En mayo de 2019 el presidente de la República, Lenín Moreno, aseguró, a través de una noticia en diario El Universo, que el "régimen anterior dejó \$75.000 millones de deuda" (El Universo 2019b).

Frente a todas estas cifras — disímiles - y ante la necesidad práctica de informar adecuadamente al mismo Fondo Monetario Internacional (FMI), en el marco del acuerdo suscrito por Ecuador el 11 de marzo de 2019, las autoridades económicas del país se vieron en la obligación de establecer con claridad, y de acuerdo con metodologías internacionales desarrolladas por el FMI, el valor exacto del endeudamiento público.

Tabla 1

\section{Deuda pública reportada al FMI*}

\begin{tabular}{|c|c|c|c|c|c|}
\hline \multirow{2}{*}{ Deuda } & $\mathbf{2 0 1 6}$ & $\mathbf{2 0 1 7}$ & $\begin{array}{c}\mathbf{2 0 1 8} \\
\text { estimada }\end{array}$ & $\begin{array}{c}\mathbf{2 0 1 9} \\
\text { proyectada }\end{array}$ & $\begin{array}{c}\mathbf{2 0 2 0} \\
\text { proyectada }\end{array}$ \\
\cline { 2 - 6 } & 43,2 & 44,6 & 46,1 & 49,2 & 46,8 \\
\hline
\end{tabular}

* En porcentajes del PIB, 2019-2020.

Las cifras de deuda pública presentadas por el FMI en el Staff Report de 2019 corresponden a deuda agregada (FMI 2019).

Fuente: FMI (2019).

En ese sentido, y luego de que se confirmó la valoración con los datos oficiales manejados hasta fines de 2017, el Ministerio de Economía y Finanzas (MEF) procedió a introducir modificaciones leves a la forma histórica del cálculo de la deuda pública. Pero, aun con este sinceramiento de las cifras, luego de un manejo político de la información de la deuda en los últimos tiempos, Richard Martínez, recién nombrado ministro de Economía y Finanzas, anunció que las obligaciones del Ecuador ascendían, entre deuda interna y externa, a más de USD 58.000 millones (El Universo 2019a).

Estas discrepancias en la información con relación a las cifras de la deuda pública, entre lo anunciado por diversas fuentes no oficiales y los reportes del MEF, resultan, cuanto menos, notorias en virtud de que las cifras de este organismo son públicas y cuentan con series históricas de varias décadas, como se evidencia en el gráfico 4 de este organismo. 


\section{Gráfico 4}

\section{Evolución de la deuda pública como porcentaje del PIB*}

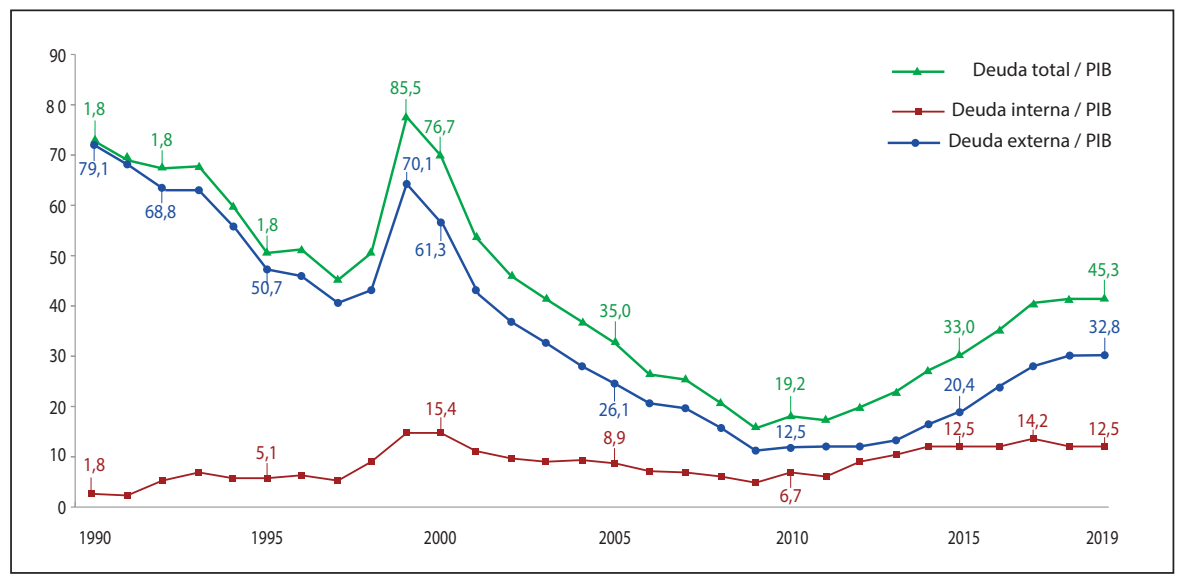

* La deuda total corresponde al concepto de deuda agregada.

En porcentajes, 1990-2019.

Fuente: Subsecretaría de Financiamiento Público (2019).

El manejo político de la deuda pública y de sus valores ha tenido repercusiones en el ámbito internacional; anuncios contradictorios de cifras desde diversos actores y, principalmente, el cuestionamiento a los procesos de financiamiento pasados, han generado desconfianza en los mercados financieros internacionales con relación a la voluntad de pago del Ecuador de sus compromisos internacionales. Esto se ve reflejado en la evolución del denominado riesgo país. ${ }^{4}$

El 5 de enero de 2018, el riesgo país alcanzó los 430 puntos, siendo su nivel más bajo desde diciembre de $2014,{ }^{5}$ producto de un manejo económico

4. El riesgo país corresponde a la percepción de los inversionistas internacionales sobre el peligro de invertir principalmente en bonos soberanos de un país, respecto del cual debe establecerse el correspondiente rendimiento financiero (tasa de interés de la deuda). El riesgo país está determinado desde el Emerging Markets Bond Index (EMBI) calculado diariamente por el banco de inversiones estadounidense J. P. Morgan.

5. Como es de conocimiento público, para fines de 2019, el riesgo país había superado los 1000 puntos y en marzo de 2020 coronó a más de 6000 . 
y de una estrategia financiera adecuada, aun cuando en 2017 el precio del petróleo ecuatoriano se mantuvo en niveles inferiores a los USD 55 por barril. En este contexto, las autoridades económicas ${ }^{6}$ estructuraron la que fuera la mayor emisión de bonos soberanos de la historia del Ecuador, para inicios de 2020, en el marco de la planificación anual de financiamiento público.

Con un riesgo país a la baja, y en una estrategia de financiamiento a través de un ejercicio de diversificación de fuentes desarrollado en los meses anteriores, se esperaba realizar esta colocación de bonos a tasas bastante más bajas que las emisiones realizadas desde 2014, año en el que Ecuador retornó al uso de este instrumento financiero. Pero el anuncio de la CGE de conformar esta veeduría ciudadana y de la realización del examen especial de la deuda externa ecuatoriana, realizado en esos mismos días, generó una percepción de desconfianza que elevó inmediatamente el riesgo país.

Para el lunes, 15 de enero de 2018, pocos días antes de la colocación de bonos, el riesgo país se había incrementado a 462 puntos debido a que los esfuerzos de la CGE habían ya llegado a los oídos de potenciales inversionistas. Fue necesaria una acción directa del ministro de Economía y Finanzas para calmar a los mercados y lograr una ligera reducción de este indicador para el jueves, 18 de enero en que se realizó la indicada colocación de bonos soberanos.

Sin este esfuerzo de convencimiento y la credibilidad que hasta entonces alcanzó el manejo económico en Ecuador y las autoridades que lo llevaron a cabo, no se hubiera logrado colocar USD 3000 millones en bonos soberanos, con una oferta que sobrepasó los USD 9000 millones, a una tasa de 7,875 \% a 10 años plazo (El Comercio 2018a).

Solo a efectos de comparación, el 24 de mayo de 2018, con el cambio de autoridades económicas, el riesgo país alcanzó los 621 puntos, es decir, un $44 \%$ por encima del registrado a inicios de enero de ese año con las anteriores autoridades y previo a los anuncios de descalificación de la deuda y del propio manejo económico de meses y años anteriores. Para fines de diciembre de 2018, el riesgo país alcanzó los 822 puntos y de ahí en adelante oscilaría con picos por encima de los 6000 puntos sin poder reducirse a los niveles de 2017 hasta la fecha de la redacción de estas líneas (14 de junio de 2019), incluso con un acuerdo con el FMI, como se puede observar en los gráficos $5 \mathrm{a}$ y $5 \mathrm{~b}$.

6. El autor se desempeñaba como ministro de Economía y Finanzas. 


\section{Gráfico 5a}

\section{Riesgo país (EMBI) y precios del petróleo (WTI) antes del acuerdo con el FMI*}

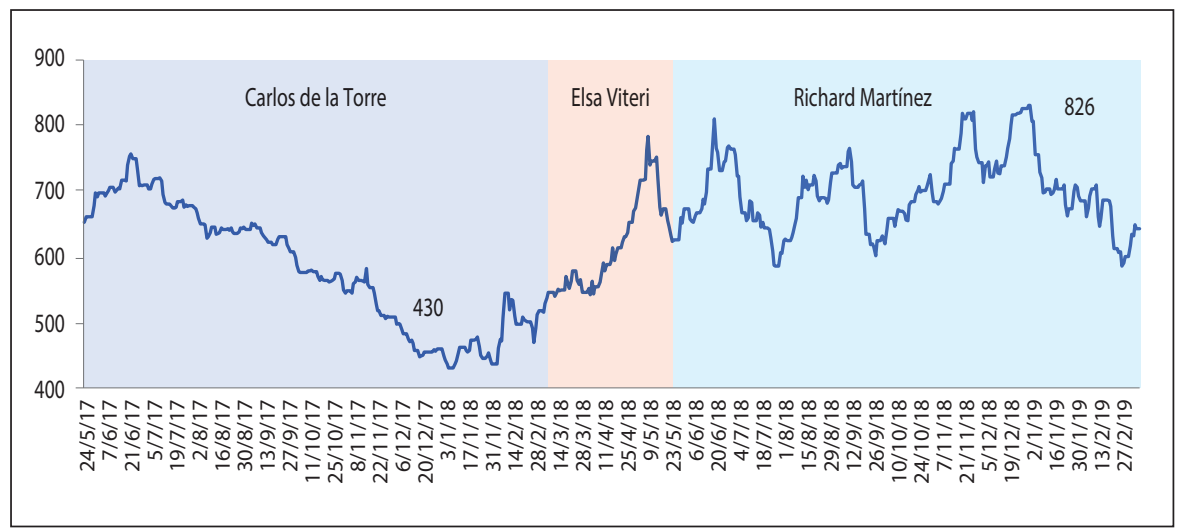

* De 24 de mayo de 2017 a 10 de marzo de 2019.

Fuente: BCE (2020).

\section{Gráfico 5b}

\section{Riesgo país (EMBI) y precios del petróleo (WTI)*}

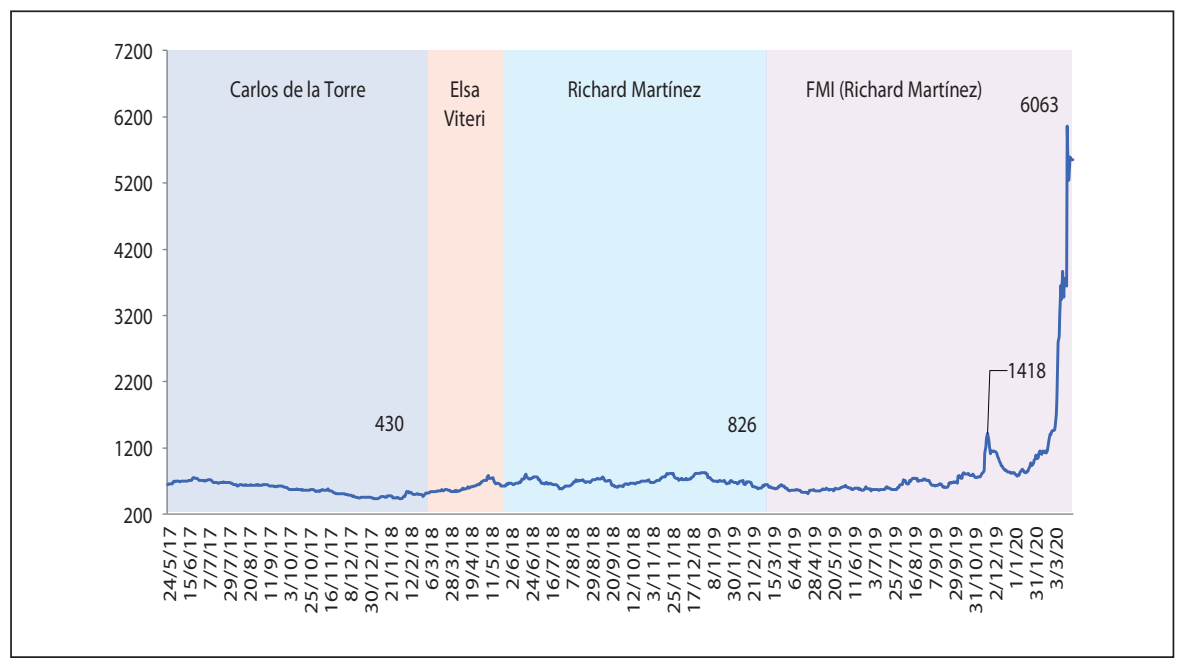

* De 24 de mayo de 2017 a 29 de marzo de 2020.

Fuente: BCE (2020). 
De varios registros del riesgo país (EMBI), se observa un primer período entre el 24 de mayo de 2017, día de inicio del período presidencial y del primer ministro, hasta marzo de 2018, cuando inició su gestión la segunda ministra, una marcada reducción de este indicador. En este caso, puede sostenerse el argumento generalizado de que los precios del petróleo (WTI) han contribuido en alguna medida a la reducción de la percepción de riesgo de los inversionistas internacionales respecto de la economía ecuatoriana, aunque existen elementos más robustos que se detallarán más adelante.

Lo que es importante evidenciar es el cambio de trayectoria desde marzo de 2018, con un riesgo país en ascenso, debido en alguna medida a las señales políticas generadas alrededor de la deuda pública, como se explicó anteriormente. Pero lo más destacable es que este ascenso en la percepción de riesgo coincide con el repunte de los precios internacionales del petróleo hasta el tercer trimestre del año ya con un tercer ministro en el cargo. De ahí en adelante, hasta diciembre de 2018, el riesgo país continuó su ascenso, para un posterior decrecimiento menor coincidente con la suscripción de un acuerdo con el FMI, que luego se revertiría sobrepasando los 1000 puntos para octubre de 2019 y alcanzando el récord histórico de 6063 a fines de marzo de 2020.

Como ya se indicó, fue en enero de 2018 cuando se alcanzó el nivel más bajo del riesgo país desde varios años atrás, y a lo largo del período actual de gobierno hasta la fecha.

\section{Metodología para el registro de la deuda pública}

De la revisión respecto de declaraciones realizadas entre 2018 y 2019 por algunos actores políticos relevantes en relación con la deuda pública ecuatoriana, se evidenció una diversidad de cifras, muchas veces muy apartadas entre sí. Esto no solo sugiere diferentes metodologías de cuantificación, sino inclusive fuentes de información distintas, en los casos en que se hubiesen hecho los respectivos ejercicios, pero, en otros casos, pudieron darse valores hasta sin ningún sustento técnico. 
La cuantificación de la deuda pública, realizada por el MEF, se realiza a partir de lineamientos metodológicos estandarizados a nivel mundial y definidos por el FMI en su Manual de Estadísticas de Finanzas Públicas (2014). De esta manera, Ecuador y la mayoría de los países del mundo cuentan con elementos comunes que permiten que sus estadísticas de finanzas públicas, y entre ellas las de la deuda pública, sean comparables en el ámbito internacional y de forma intertemporal.

En el marco del artículo IV del Convenio Constitutivo del FMI (2011), del cual Ecuador es parte, junto con 188 países, cada año las misiones de este organismo multilateral en sus visitas a los países miembros, revisan, entre otras cosas, la calidad de sus estadísticas económicas. ${ }^{7}$

Los estándares metodológicos internacionales en materia de estadísticas fiscales son recogidos en la normativa ecuatoriana vigente, principalmente en el Código Orgánico de Planificación y Finanzas Públicas y su Reglamento General (EC 2010). Este último, en relación con la deuda pública, en su artículo 135 establece:

Información relativa al endeudamiento público.- (Reformado por el art. 4 del D.E. 1218, R.O. 869-2S, 25-X-2016).- El Ministerio de Finanzas tendrá la responsabilidad de vigilar que el monto total del saldo de la deuda pública del conjunto de entidades y organismos del sector público, no sobrepase el cuarenta por ciento ( $40 \%)$ del producto interno bruto (PIB); para lo cual, el cálculo respectivo se lo efectuará sobre la base de los Estados Consolidados de Deuda Pública correspondiente a cada ejercicio fiscal, de conformidad con el Manual de Estadísticas de las Finanzas Públicas del Fondo Monetario Internacional.

Sobre la base de esta definición normativa, se colige más de una categoría de deuda pública, ya que, en este caso, el cálculo referido y el límite que se establece corresponden al concepto de deuda consolidada.

Respecto de esta categoría o medición particular de la deuda pública, el FMI $(2014,70)$ parte de la explicación y necesidad de la consolidación. Para el efecto, establece:

7. El literal b) de la sección 3 - Supervisión de los regímenes cambiarios-, del art. IV del Convenio Constitutivo del FMI establece que "Los países miembros proporcionarán al Fondo la información necesaria para ejercer esa supervisión", lo cual en la práctica se ha extendido a todo el manejo de su política económica y no se ha limitado a los regímenes cambiarios. 
Razones de la consolidación

$3.158^{8}$ La principal razón de la consolidación reside en la utilidad analítica de las estadísticas consolidadas: la consolidación elimina los efectos distorsionadores que sobre los agregados tienen los distintos mecanismos administrativos usados por los países o a través del tiempo [...]

3.159 La consolidación excluye la interacción económica dentro del grupo de unidades institucionales y presenta solo aquellos flujos o saldos que implican interacciones con todas las demás unidades institucionales de la economía y con el resto del mundo.

3.160 la consolidación evita la doble contabilización de flujos o posiciones de saldos al interior de un grupo de unidades institucionales [...]

3.161 conceptualmente, la consolidación implica la eliminación de todos los flujos intra e intergubernamentales y todas las relaciones deudor-acreedor entre las unidades o entidades que se combinan.

\section{A esta explicación, el FMI $(2014,71)$ agrega de forma taxativa las tran- sacciones que deben consolidarse en su cuantificación, para lo cual establece:}

3.163 Las siguientes transacciones mayores, otros flujos económicos y posiciones de saldos en activos financieros y pasivos, en probable orden de importancia, deben consolidarse:

- Préstamos.

- Títulos de deuda.

- Otras cuentas por cobrar/por pagar.

Adicionalmente, respecto de la consolidación del sector gobierno general, el FMI (2014, 17-18) indica que:

$2.58 \mathrm{El}$ sector gobierno general comprende las unidades institucionales residentes cuya actividad primaria es cumplir las funciones de gobierno [...] El sector gobierno general comprende a:

- Todas las unidades de gobierno de los gobiernos central, estatales, provinciales, regionales y locales, y los fondos de seguridad social (véanse los párrafos 2.76-2.103) impuestos y controlados por dichas unidades.

- Todas las ISFL no de mercado controladas por unidades de gobierno (véase el párrafo 2.83).

2.59 El sector gobierno general no incluye a las sociedades públicas.

8. La numeración que antecede los textos del Manual de Estadísticas de Finanzas Públicas 2014 corresponde a cada párrafo como medio para su fácil identificación. 
De esta manera, las directrices metodológicas internacionales de uso general que la normativa vigente en Ecuador hasta 2018 integró para la forma de cálculo de la deuda pública, no dejan ningún espacio para interpretaciones ni para cómputos distintos que no correspondan a estas definiciones.

Con la aplicación de estos lineamientos metodológicos, la deuda pública consolidada del Ecuador se incrementó de 10,7 \% del PIB en 2009 a 28,4 \% al cierre de 2017, por lo que su nivel se mantuvo en el marco de la normativa vigente a esta última fecha (gráfico 6).

\section{Gráfico 6}

\section{Deuda consolidada del gobierno central*}

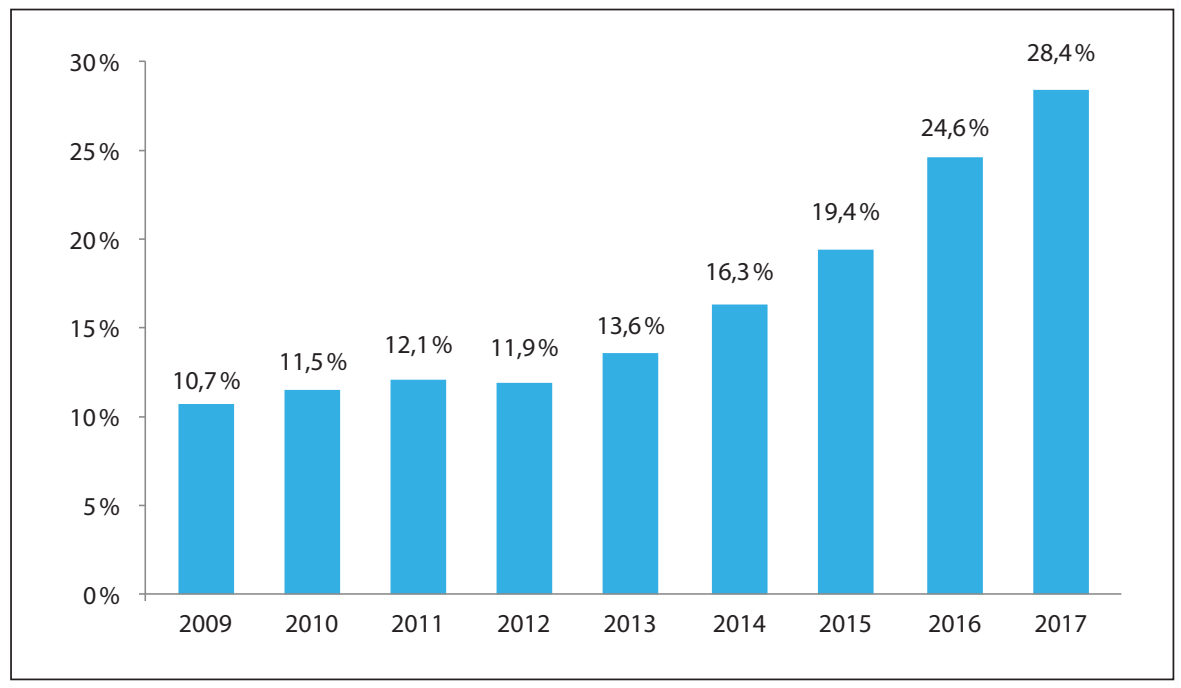

*En porcentajes, 2009-2017.

Fuente: CEPAL (2018). ${ }^{9}$

Por otra parte, el endeudamiento público se ha presentado desde ciertos sectores como un elemento negativo del manejo económico, especialmente en años anteriores. Como ejemplo, el exministro de Economía y Finanzas,

9. Se han tomado las cifras de la CEPAL como una entidad externa y neutral a las posiciones locales sobre la cuantificación y valores de la deuda pública ecuatoriana. 
Mauricio Pozo, declaraba en el medio digital Ecuador en Vivo (19 de marzo de 2018) que "el crecimiento 'demencial' de la deuda se debe al desorden fiscal que en los últimos años se ha venido ejecutando en Ecuador, con la falta de coherencia en la política pública que mantiene el endeudamiento como su principal aliado sumergiendo al país en una crisis económica".

Ya desde un análisis técnico, evaluación correcta de variables económicas se realiza en términos relativos como proporción del PIB o de otras variables relevantes, pero nunca en términos absolutos y con calificativos. En el caso de la deuda pública, medida en relación con el PIB, incluso su evaluación adecuada debería realizarse comparándola con otros países o entre distintos períodos. Por ello, para precisamente relativizar su magnitud en comparación con otros países de la región, se aprecia que a 2017 la deuda consolidada del gobierno central del Ecuador como porcentaje del PIB con 28,4\%, no alcanzaba siquiera la media de América Latina de 38,8 \% (gráfico 7).

\section{Gráfico 7}

\section{Deuda consolidada del gobierno central $^{*}$}

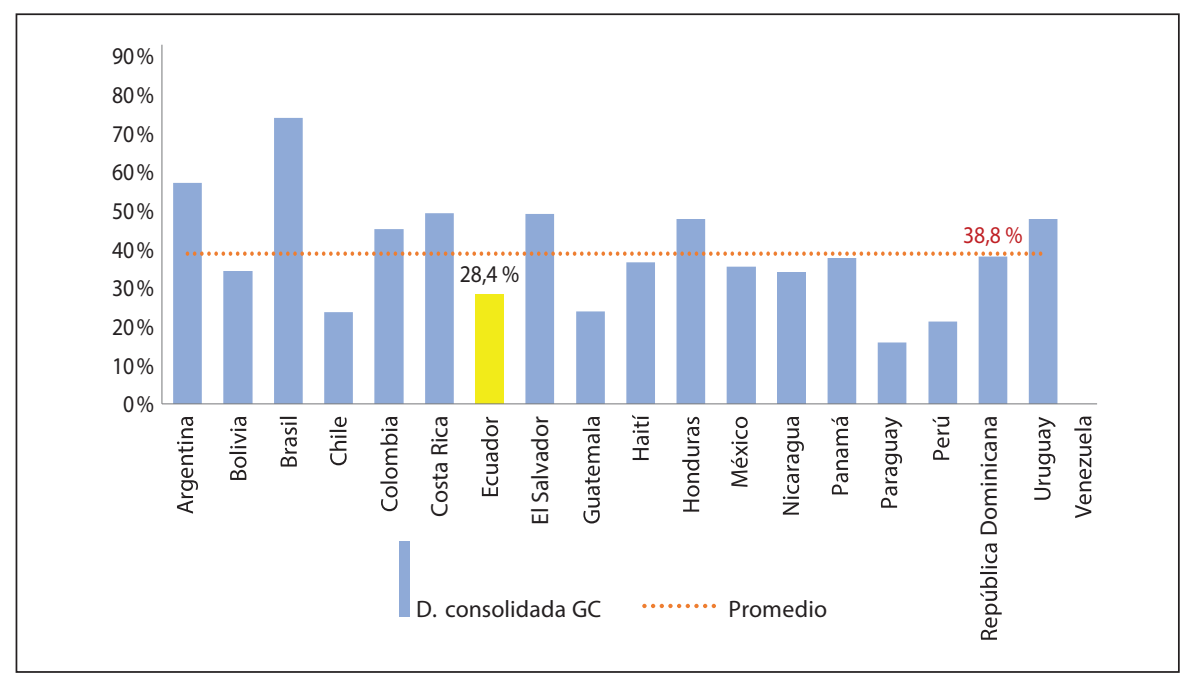

* En porcentajes, países de América Latina 2017.

Fuente: CEPAL (2018). 
Por otra parte, un elemento importante a considerarse es que la mayor parte de la deuda consolidada del gobierno central del Ecuador corresponde a deuda externa, cuando en la mayoría de los países de la región, la mayor proporción de su deuda pública es de origen interno (gráfico 8).

\section{Gráfico 8}

\section{Deuda interna*}

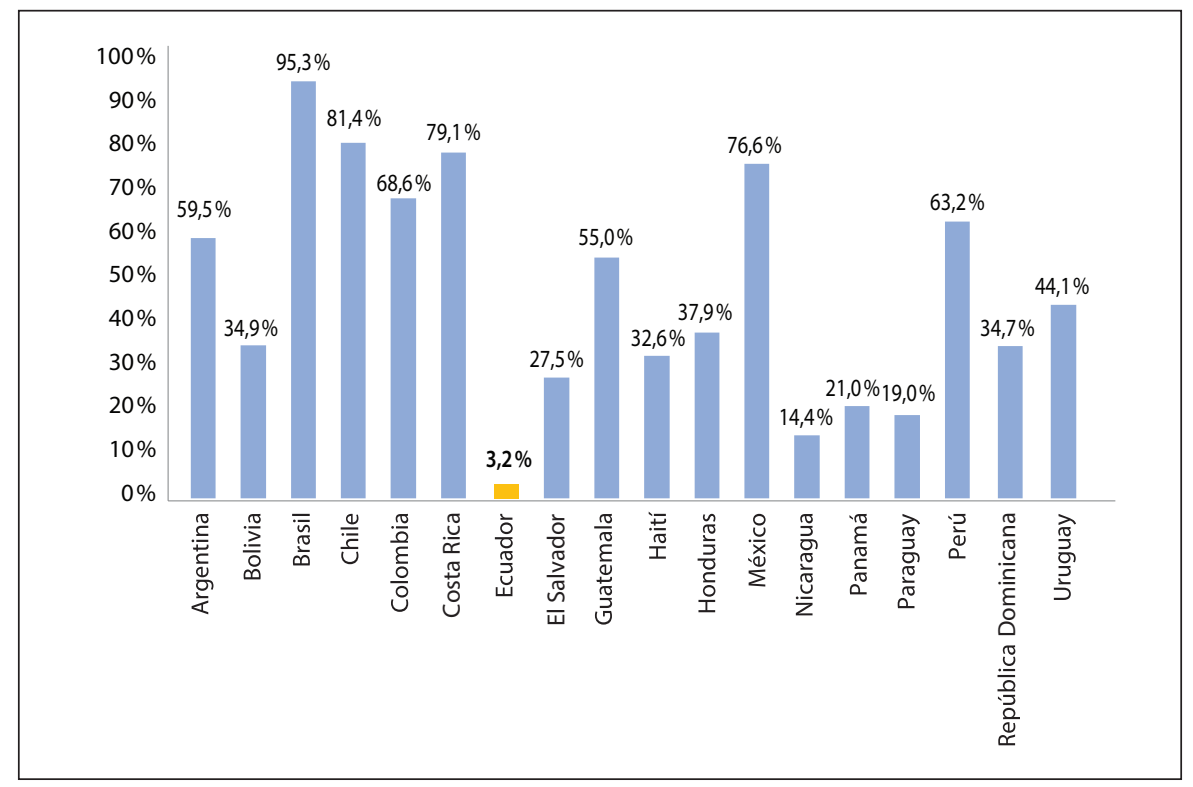

* En porcentajes de la deuda del gobierno central; países de América Latina y el Caribe, 2017. Fuente: CEPAL (2018).

Este dato es relevante en la medida en que el Gobierno ecuatoriano no se ha podido beneficiar de un mayor acceso a financiamiento local que, evidentemente, será siempre en mejores condiciones que el financiamiento externo. Asimismo, es importante indicar que, en dolarización, un nivel elevado de financiamiento externo significa una elevada salida neta de divisas que, de otra manera, sería sustancialmente menor, ya que, con el repago de la deuda, no solo se devuelve el capital que ingresó a la economía, sino que deben pagarse también los intereses al exterior. 
En cuanto a esta situación, es importante destacar que con la aprobación de la Ley Orgánica para el Fomento Productivo, Atracción de Inversiones, Generación de Empleo, y Estabilidad y Equilibrio Fiscal (EC 2018) se suprimió la atribución del Banco Central del Ecuador y del Instituto Ecuatoriano de Seguridad Social de comprar títulos valores al ente rector de las finanzas públicas; es decir, se eliminó la posibilidad de que la caja fiscal pueda obtener financiamiento desde las principales fuentes de liquidez doméstica, como sí sucede en otros países.

\section{El déficit fiscal}

Uno de los lineamientos característicos del Consenso de Washington, definición establecida sobre un conjunto de medidas económicas promovidas por la institucionalidad multilateral asentada en la capital estadounidense, es el manejo fiscal austero fundamentado en la reducción del gasto público. Martínez y Reyes $(2012,47)$ establecen como segundo punto la reordenación de las prioridades del gasto público "a partir del recorte al gasto público para reducir el déficit presupuestario sin recurrir a los impuestos".

Desde una perspectiva contable, pero no económica, de un manejo adecuado de las finanzas públicas, aparece como razonable la reducción del gasto público en valores absolutos y su consecuente efecto de un menor déficit fiscal. Desde esta lógica reducida a un simple manejo de cuentas, ambas variables son usualmente posicionadas negativamente sin considerar los factores positivos de su incidencia en las variables relacionadas directamente con el bienestar social. Es así como su corrección aparece como prioridad de la política económica desde ciertas visiones particulares, pero descuida una consideración fundamental.

La cuantificación de muchas variables económicas se realiza usualmente en términos relativos al PIB a efectos de dimensionarlas en relación con el tamaño de la economía, y hacerlas comparables en el tiempo y entre países. Con esta precisión, el déficit se establece de la siguiente manera:

$$
\text { Déficit fiscal }=\frac{\text { Gastos-Ingresos }}{P I B}
$$


En una primera aproximación (ecuación 2), el déficit fiscal ${ }^{10}$ se reduciría si se restringen los gastos o se incrementan los ingresos, o ambas cosas, mientras el PIB se mantenga constante. De esta manera, los lineamientos del Consenso de Washington orientados a la reducción del gasto público e incremento de ingresos vía ampliación de impuestos, parecerían tener sentido, como indican Martínez y Reyes $(2012,47)$ cuando citan el tercer punto relativo a la reforma fiscal, la que "debía emprenderse para ampliar la recaudación tributaria, disminuir el gasto público y, en consecuencia, remediar el déficit presupuestario".

$$
\downarrow \text { Déficit fiscal }=\frac{\downarrow \text { Gastos }-\uparrow \text { Ingresos }}{\overline{P I B}}
$$

Lo que no contempla este enfoque es el efecto del gasto público en el crecimiento del PIB a través de los denominados multiplicadores. Es así como el gasto público desde sus componentes: gasto corriente (consumo del gobierno), inversión pública y transferencias, genera dinámicas en la economía que, a través de producción y consumo resultantes, multiplican los recursos inyectados desde el Estado. En un estudio reciente para Chile, Fornero, Guerra-Salas y Pérez (2019) establecen que el multiplicador del gasto total en ese país está en torno a 1, mientras que el que corresponde al consumo de gobierno y la inversión pública alcanzan valores en torno a 2 y las transferencias, menos que 1.

En el caso específico de la inversión pública, estos resultados implican que por cada unidad monetaria que el Gobierno chileno destina a este rubro, se generan dos unidades monetarias en términos de producción. De esa manera, queda claro que el gasto público en general, y su componente de inversión, impulsan a la producción mientras que su reducción puede comprometer el crecimiento del PIB, y una eventual contracción de la economía que resulte de una política de austeridad, terminará incrementando el déficit fiscal (ecuación 3).

$$
\uparrow \text { Déficit fiscal }=\frac{\downarrow \text { Gastos }-\uparrow \text { Ingresos }}{\downarrow P I B}
$$

10. Si su signo es negativo, corresponde a superávit. 
Por ello, un manejo fiscal apropiado y desarticulado de la reducción contable entre el contraste de ingresos y gastos, hasta puede permitir el incremento en el gasto público, y por tanto del déficit absoluto, mientras el PIB se incremente a una mayor tasa. Con ello, el déficit fiscal relativo se reduce (ecuación 4), cumpliéndose un objetivo deseable de la política fiscal por partida doble ya que a la vez se impulsa el crecimiento económico.

$$
\downarrow \text { Déficit fiscal }=\frac{\uparrow \text { Gastos-Ingresos }}{\uparrow P I B}
$$

Este enfoque, implementado como estrategia durante el segundo semestre de 2017, permitió que la economía ecuatoriana, que se había contraído con una reducción del PIB de -1,6\% en 2016, para el cierre del año siguiente alcance un crecimiento de $+2,4 \%$. A la par, se logró reducir el déficit fiscal del Sector Público No Financiero (SPNF) como proporción del PIB del $-7,32 \%$ al $-4,46 \%$, mientras el gasto corriente devengado del SPNF como proporción del PIB se incrementó de 26,62 al 27,24 \%. Con ello, se evidencia que aun con un incremento del gasto corriente del SPNF se logró reducir el déficit fiscal gracias a políticas que favorecieron el crecimiento de la producción.

Tabla 2

Variables macroeconómicas*

\begin{tabular}{|l|c|c|c|}
\hline & $\mathbf{2 0 1 6}$ & $\mathbf{2 0 1 7}$ & \\
\hline Variación del PIB & $-1,60 \%$ & $2,40 \%$ & A \\
\hline Gasto corriente SPNF como \% PIB & $26,62 \%$ & $27,24 \%$ & V \\
\hline Déficit fiscal SPNF como \% PIB & $-7,32 \%$ & $-4,46 \%$ & \\
\hline
\end{tabular}

* En porcentajes, 2016 y 2017.

Fuente: BCE (2020). 


\section{El gasto público y el tamaño del Estado}

Como se evidenció en líneas anteriores, desde ciertos sectores de opinión se pretende posicionar la idea de que el Estado ecuatoriano es obeso (Carrera 2020), con la utilización de este adjetivo de forma absoluta sin ninguna comparación o relativización. Es evidente que el uso de calificativos como este, que en el imaginario ciudadano tienen connotaciones negativas, obedece a una intencionalidad política y no a una descripción adecuada de la realidad. Al efectuarse el contraste correspondiente del tamaño del Estado ecuatoriano respecto del conjunto de economías de América Latina y el Caribe, la CEPAL, para 2017 demuestra lo siguiente:

\section{Gráfico 9}

\section{Gasto público total y préstamo neto*}

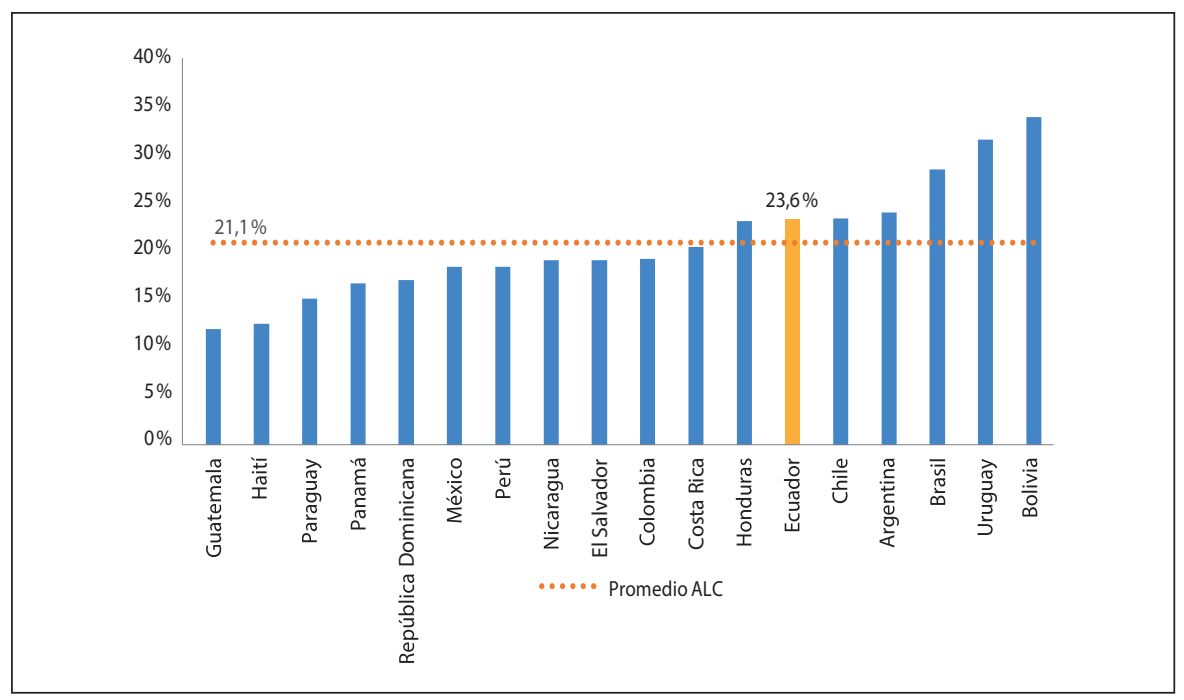

* En porcentajes respecto del PIB; países de América Latina y el Caribe, 2017.

Fuente: CEPAL (2019). 
Como se observa, Ecuador presenta un valor de 23,6\% del PIB para el gasto público y préstamo neto en 2017 apenas por encima del promedio de los países de América Latina y el Caribe; lo cual denota que la adjetivación en relación con el tamaño del Estado, al menos desde esta valoración, no le puede ubicar en ningún extremo respecto de este conjunto de países de la región.

\section{Conclusiones}

La dependencia de los ingresos del PGE en las exportaciones petroleras presenta una trayectoria decreciente en los últimos años, pero mantiene una fuerte relación con los precios internacionales del crudo.

No hay sustento técnico para considerar que el Estado ecuatoriano está sobreendeudado y la mediatización de esta posición argumentada desde ciertos sectores ha afectado la imagen internacional del país.

En general, el riesgo país ha evolucionado en sentido inverso a los precios del petróleo, excepto durante varios meses de 2018, cuando aun con un incremento de estos precios, el riesgo país también se incrementó. Con ello se evidencia que existen otros factores relevantes para los mercados financieros internacionales en cuanto a la solvencia económica del Ecuador.

La diversidad de cifras del endeudamiento del gobierno, difundidas por distintos actores en los últimos tiempos, no se ajustan a la normativa vigente ni a estándares internacionales, por lo que afirmaciones realizadas en cuanto a que el límite legal del $40 \%$ del PIB fue superado en años anteriores, no corresponden con la realidad.

El nivel de deuda pública consolidada del Ecuador, en el contexto de América Latina, no justifica el argumento de sobreendeudamiento publicitado en los últimos años.

En el contexto regional, Ecuador es uno de los países con mayor proporción de su deuda pública dependiente de financiamiento externo, lo cual no resulta adecuado al no contar con moneda propia, ya que el repago de dicho financiamiento resulta en una salida neta de divisas al exterior.

La política fiscal de austeridad, orientada al objetivo contable de reducción del déficit fiscal a través de la reducción del gasto público, lo único que 
logra es el estrangulamiento de la economía al coartar el crecimiento del PIB, sin que se resuelva lo que se pretende, a la par que se generan impactos negativos en el bienestar social.

Una política fiscal coherente, demostrada con evidencias durante 2017, consiste en mantener la inversión pública como factor multiplicador de producción, aun con un incremento del gasto público, pero con un incremento mayor del PIB se puede lograr la reducción progresiva del déficit fiscal mejorando, a la vez, las condiciones económicas y sociales de la población.

La adjetivación negativa respecto de las variables fiscales, en especial respecto del gasto público y del tamaño del Estado ecuatoriano, no corresponde con el contraste realizado respecto de otras economías de la región.

\section{Referencias}

Carrera, Jaime. 2020. "Aquí están las pruebas del Estado obeso". 4 Pelagatos. 12 de marzo. Accedido mayo 2020. https://tinyurl.com/y8svtvej.

Comisión Económica para América Latina y el Caribe (CEPAL). 2018a. Balance preliminar de las economías de América Latina y el Caribe. Santiago: CEPAL. Accedido abril 2020. https://tinyurl.com/yaavyfzb.

---.2018b. La política fiscal es un instrumento fundamental para alcanzar la Agenda 2030 y un crecimiento inclusivo con mayor igualdad. Santiago: CEPAL. Accedido abril 2020. https://tinyurl.com/y8clty4l.

---. 2019. Panorama fiscal de América Latina y el Caribe. Políticas tributarias para la movilización de recursos en el marco de la Agenda 2030 para el Desarrollo Sostenible. Santiago: CEPAL. Accedido abril 2020. https://tinyurl.com/ydx5g5bb.

EC. 2010. Código Orgánico de Planificación y Finanzas Públicas (COPLAFIP). Registro Oficial, Segundo Suplemento 306, 22 de octubre.

---. 2018. Ley Orgánica para el Fomento Productivo, Atracción de Inversiones, Generación de Empleo, y Estabilidad y Equilibrio Fiscal. Registro Oficial, Suplemento 309, 21 de agosto.

EC Banco Central del Ecuador (BCE). 2020. Información estadística mensual. Quito: BCE. Accedido mayo 2020. https://tinyurl.com/y6ljqz95.

EC Ministerio de Economía y Finanzas. 2019. Subsecretaría de Crédito Público. Boletín de deuda pública, marzo. Quito: Ministerio de Economía y Finanzas. Accedido abril 2020. https://tinyurl.com/yy2kdwdn.

El Comercio. 2018a. "Contraloría integró veeduría sobre deuda pública interna y externa”. El Comercio. 9 de enero. Accedido marzo 2020. https://tinyurl.com/y7y7tkjd. 
---. 2018b. "Ecuador colocó USD 3000 millones en bonos soberanos". El Comercio. 18 de enero de 2018. Accedido marzo 2020. https://tinyurl.com/y7gy9u8p.

---. 2018c. "Deuda: Contraloría recogió observaciones de veedores". El Comercio. 3 de abril de 2018. Accedido marzo 2020. https://tinyurl.com/yd8tu97x.

---. 2018d. "El informe sobre la auditoría a la deuda pública, en revisión final”. El Comercio. 3 de abril. Acedido marzo 2020. https://tinyurl.com/y8x4djh3.

El Universo. 2019a. "Obligaciones económicas de Ecuador ascienden a más de $\$ 58.000 \mathrm{mi}-$ llones, según ministro". El Universo. 18 de mayo. Accedido marzo 2020. https://tinyurl. com/yacd4y4k.

---. 2019b."Régimen anterior dejó \$ 75.000 millones de deuda, aseguró el presidente Lenín Moreno". El Univeso, 17 de mayo. Accedido marzo 2020. https://tinyurl.com/y9n8b922.

Fondo Monetario Internacional (FMI). 2011. Convenio constitutivo del Fondo Monetario Internacional 1944. Washington D. C.: FMI. https://tinyurl.com/y7ecprl6.

---. 2014. Manual de estadísticas de finanzas públicas. Washington D. C.: FMI. https://tinyurl. $\mathrm{com} / \mathrm{y} 8 \mathrm{~h} 3 \mathrm{db} 9 \mathrm{j}$.

---. 2019. Ecuador Staff Report for the 2019 Article IV consultation and request for an Extended Arrangement under the Extended Fund Facility. Washington D. C.: FMI. https:// tinyurl.com/ycuuqrqp.

Fornero, Jorge, Juan Guerra-Salas y Camilo Pérez. 2019. "Multiplicadores fiscales en Chile". Economía chilena 22 (1): 58-80. https://tinyurl.com/y5w7rtem.

Martínez Rangel, Rubí, y Ernesto Reyes Garmendia. 2012. "El Consenso de Washington: la instauración de las políticas neoliberales en América Latina". Política y Cultura 37: 35-64. https://tinyurl.com/y4r8kfr3.

Pozo, Mauricio. 2018. "Crecimiento 'demencial' de la deuda se debe al desorden fiscal". Ecuador en Vivo. 19 de marzo. Accedido mayo 2020. https://tinyurl.com/y7et98ef. 